\title{
Talking to oneself: using autobiographical internal dialogue to critique everyday and professional practice
}

Hughes, G. (2009) Talking to oneself: using autobiographical internal dialogue to critique everyday and professional practice. Reflective Practice, 10,4: 451- 463.

\begin{abstract}
This article explores how autobiographical narrative about everyday activities can stimulate critical reflection. A re-interpretation of Schön's stages of reflective practice is used to explore some examples from autobiographical writing about the everyday practice of carrying a bag to illustrate literary devices which enable self-interrogation and internal dialogue. Such writing can mimic the dialogue with a peer or coach to generate new perspectives and sometimes change in habitual practice. Implications of using both reflection on everyday life and creative autobiography for the development of professionals are finally discussed.
\end{abstract}

Keywords: self-critique, internal dialogue, everyday practice, autobiography, reflection

\section{Introduction}

There are three things extremely hard: steel, a diamond, and to know one's self. (Benjamin Franklin, 1750).

Professionals such as medics, architects or teachers frequently use the concept of reflection on practice as they seek to capture the tacit knowledge that is essential for both entry into the profession and continuing professional development. Many have been influenced by the work of Donald Schön (1984) and his popular concept of the reflective practitioner. But reflective practice is more than a process for capturing professional knowledge, it is also about learning and change. A change in practice provides the evidence that learning has taken place (Jarvis, 1995), but habitual practice is often hard to shift. Most people are poor at self-evaluation (Dunning, et al, 2004) and many of us have to work hard to achieve the self-awareness needed to change practice. Reflection is not an activity to be underestimated.

There are many ways of engaging in reflection and different levels of criticality. Reflection means different things to different people (Moon, 2000) and can range from description of events to a deep and critical analysis of self. Reflection can occur though group discussion, mentoring and in reflective writing (Hobbs, 2007) as well as in meta-learning processes such as personal development planning or portfolio building (Clegg, Tan \& Saeidi, 2002). This article looks at one form of reflective writing: autobiographical writing, and explores how internal dialogue using an imagined 'other' can enable self-indulgent writing to evolve into self-critical reflection.

A group of researchers, including me as author of this paper, explored everyday practice used autobiographical reflection as a method for collecting data. We proposed that while writing about professional practice is often completed in the context of professional development or accredited learning, writing about an everyday experience could be very creative and less restricted. The project studied people's autobiographical writing on the everyday practice of carrying a bag. Through this autobiographical writing, the authors generated new knowledge and insights into the 
management of complex lives through multiple use of bags, pockets, compartments and organisational devices (diaries or electronic gadgets).

Schön's work on reflection on professional practice can be applied to everyday practice with some limitations. The article next considers how far the process of producing these autobiographies mapped onto Schön's steps for reflection-in-action. But, the process of creating autobiographical texts such as these does not follow quite such linear stages and there is an emotional component that Schön does not include. Selected illustrations from the project demonstrate that internal dialogue provided a very effective device for stimulating self-critical reflection in some cases at least prompting new action. Such internal dialogue can mimic or supplement dialogue with other people.

Insights from everyday reflection can be applied to the reflective professional. Reflection on everyday events is easier than reflection on professional activity because it does not have the gravitas, serious repercussions and gate-keeping implications of professional activity. Internal dialogue could thus be a useful route into reflective writing for those who are unaccustomed to reflective work in their local communities. The final section explores how use of internal dialogue can be used for trainee lecturers and other professionals.

\section{Some literature on doing reflective practice}

\section{Steps to becoming a reflective practitioner}

Schön's (1984) first book on reflective practice arose because of his interest in a dichotomy between the 'hard' knowledge of scientists and academics and the 'soft' knowledge and artistry possessed by professionals. He argued that a technical-rational approach to professional knowledge, where researchers produce knowledge and theory of how to solve problems and practitioners put theory into practice, is not useful. This is because professional practice, like everyday practice, is characterised by uncertainly, complexity and conflict which does not fit neatly into the model of technical rationality. Professionals often deal with a situation where there is no clear-cut solution. The teacher could be faced students who are unpredictable in their motivation and ability to learn, or the doctor could be presented with puzzling symptoms which do not fit a textbook diagnosis. Experienced professionals know more about their practice than they can say and Schön calls this tacit knowledge 'knowledge-in-practice'. But this type of professional knowledge is not easily recorded and disseminated.

Schön proposed reflection-in-action as an alternative to the technical-rational approach to professional knowledge. People frequently think about what they are doing while they are doing it and through this process may solve a problem. Such "reflection-in-action" is based on what we might call a hunch or intuition: it is like jazz players listening to each other and improvising new harmonies in response to each other as they perform. It is not easy to explain how the musicians do this but clearly drawing on experience is important. It is reflection in action which enables us to deal with situations where there is novelty and uncertainty, for example, a teacher is able to respond to a disaffected learner in the classroom.

People do reflection-in-action all the time otherwise they would not be able to keep a conversation going. Such 'thinking on one's feet' draws on repertoires of experience and knowledge. But Schön 
(1991) explains that learning to become a professional requires learning to think like a teacher or architect and that this is something that students have little idea about, at least to start with, as since they do not have much of a repertoire of experience. Schön proposes that a dialogue between coach and student is needed for learning to occur. He developed a ladder of reflection to guide the coach and student through stages in his example of coaching students how to do architectural design.

stage 1. Action e.g. designing a building

stage 2. Description of the design

stage 3. Reflection on description of design

stage 4. Reflection on reflection on description of design

(adapted from Schön, 1991:115)

The role of the coach is then to take students through these stages, and in particular the last reflective stage, with the aim that the student will learn to think and act in the manner of an expert professional.

\section{Developing understanding of reflective practice: some critiques of Schön}

Schön's work has been critiqued because it does not allow for the complexity of ways in which people reflect and consider their actions. Firstly, while sometimes reflection is immediate, at other times sometimes it is deferred with a need for distance from the event. The action which follows a reflection can also be instantaneous or postponed (Clegg \& Saeidi, 2002). Commentators on Schön have termed this distancing process reflection-on-action which occurs after the event (Brockbank \& McGill, 1998). But, Schön argues that the four stages of reflection are the same.

Secondly, the reflective individual does not act in isolation from peer and other communities and there are social models for learning which do not depend solely on dialogue with a coach or teacher. Wenger (1998) has provided a very different model for professional learning. Building on the apprenticeship model of situated learning, He describes social learning as mutual engagement with others and participation in communities of practice which have a common enterprise or purpose and which negotiate their own meanings and repertoires. He also argues that taking part in a learning community of practice involves identity transformation as members move from peripheral to full membership of the learning community. A novice professional becomes a core member by engaging with those who are more experienced in a professional community of practice.

Reflective practice induced through individual coaching and learning through participating in communities are not mutually exclusive. An individual's reflection on practice must draw on the norms and agreed behaviours of the professional community in which s/he is participating. Thus, a teacher's reflections will be influenced by the practice of others in the local school, university or college environments as well as by current thinking on what is good educational practice and peer support for reflection will be invaluable.

Thirdly, Brockbank \& McGill (1998) critique Schön's hierarchical approach of having sequenced stages. Any reflective process is unlikely to be as linear as the above model suggests. The 
involvement of others whether, as a coach, mentor or peers, might occur intermittently and not at a particular stage. For example, reflective writing is usually an iterative process requiring drafting and re-drafting with descriptions and reflections occurring at any time. The easy of use of ICTs (information and communication technologies) for cut and paste, inserting and deleting and multiple editing of electronic texts means it is impossible to distinguish an original from multiple reworking and copies (Usher and Edwards, 2000).

Finally, there is an emotional level needed to reflect on one's actions and such emotions may be a block to deeper reflection (Brockbank and McGill, 1998). Psychologists suggest that writing about events accompanied by emotional responses helps people gain new insight into their actions (Pennebaker \& Graybeal, 2001). However, writing that is not intended for public consumption such as a personal journal or diary can range from the negatively self-indulgent to the positively liberating. This is why the role of a mentor or coach or community of peers that is sensitive to the affective side of learning is so valuable. But, the affective is often dismissed in education where the emphasis is on the cognitive (Mortiboys, 2005) and people might be reluctant to share highly emotive reflections with others or feel that this is inappropriate at professional and higher levels. Thus, reflection can be superficial, uncritical and not necessarily based on critical thinking.

\section{Critical reflection as transformation through critical thinking}

Schön's ideas on reflective practice have been developed to emphasise the importance of selfcritique and the use of 'critical' needs some attention. Critical thinking is a term which is widely used in education, particularly higher education, but which has multiple meanings (Moon, 2007). Being critical is often assumed to be synonymous with providing a negative perspective and in educational circles it is assumed to be about seeking counterarguments, but this is somewhat limiting. Moon argues that critical thinking concerns examining an idea in depth and challenging the obvious or received wisdom. She also explains how critical thinking encompasses self-critique and reappraising evidence of effectiveness of practice and taking new action. It is this drawing on new evidence to undertake new action which I refer to in the term critical reflection on practice.

However, while people can be helped towards being critical of self and re-evaluating their actions through reflective processes, planning for and taking new action does not necessarily follow. In a study of guided reflection of trainee teachers using videotapes of classroom teaching, reflections involving descriptions of habitual actions and expression of emotions were common whereas transformative statements about new actions or behaviours were very rare (Husu et al., 2008). If transformation or change of action is key to a critical reflection on practice then some new ways of enabling this to happen would be very useful for professional practice. Because of its literary creativity, and because it legitimises rather than obscures emotional responses, autobiographical writing has much potential and I turn to this next.

\section{Researching 'bag' stories: applying Schön' work to reflection on everyday practice}

\section{Using autobiography to research everyday life}

The research project 'People and Their Things (PATT)' used autobiographical writing to enable people to reflect on the everyday experience of carrying a bag. The aim was twofold: firstly, to 
provide data on people's everyday actions of bag carrying and secondly, to examine what the writers learnt about themselves in the process. It is the second aim which is the concern of this paper. There was no assumption that these accounts would be critically reflective. Yet, while some accounts were mainly descriptive, what emerged were some unprompted critical reflections which surprised the group of researchers who commissioned the pieces.

The practice of organising one's everyday life is mediated by tacit knowledge in the same way as professional practice and provides an opportunity for anyone to do reflective practice. No-one tells us (as adults) what to carry in our bags or pockets. There is no literature advising one on how to organise a handbag (purse) and what to carry. It is assumed to be a matter of individual preference and practice. Items such as keys or wallet or money are highly likely to be carried around, but from then on we have pretty much a free range to take what we wish on our travels. Dependant on the communities to which we belong, there will be individual necessities like medicines or spectacles, or gendered artefacts such as those for accompanying children or cosmetics to maintain appearance and consequently two people's bags or pockets are unlikely to contain exactly the same items.

In using autobiographical writing as a research tool, we recognised that that autobiography could be interpreted anywhere along the spectrum between an accurate description of events to a deliberately fictitious self-narrative (Henwood et al., 2001). However, we agreed that accounts would inevitably be partial with writers omitting to mention potentially embarrassing details and I would go further to say that recall of events is a construction and has no more factual status than biography (Stanley, 1992). We expected that the level of personal and emotional detail would vary widely and indeed it did: some people were highly self-critical about items they carried almost to the point of being confessional, while others focussed on providing a factual list of bag contents. Gender is an interesting factor in the interpretation of autobiographical writing. There is a long history of personal autobiographical writing by women (for example, Millet, 1974; Steedman, 1987). Many of the more emotional accounts were written by women and here the intimacy of some of the stories does not surprise the reader, but there were also some very personal reflections written by males and these were often the most transgressive.

\section{Collecting the bag stories}

The bag stories were collected in two batches. The first round of writers was from the PATT project group of eight researchers from different disciplinary backgrounds. We agreed to tell the story of our bag(s) used/carried in the course of a particular day, and describe the contents. We selected a particular date and agreed to write our bag story on that day. We met several times and exchanged stories in the group and discussed what we thought was particularly significant about each one and, although only three of us previous experience of reflective autobiographical writing, we encouraged each other to reflect critically. Some of us were aware of the possible sociological analysis of the accounts in that they might provide insights into gender, class, sexuality and generation while others were interested in topics such as spaces and places (geography), technologies of surveillance and the carrying of personal mementos. We expected that our subsequent analysis of this writing would be greatly informed by our own academic specialisms-in my case education.

Following the successes of these stories in producing rich data for analysis, each researcher invited two or more people, some with similar academic backgrounds to ourselves and others very 
different, to write a bag story on another date for a second round. Writers were not expected to provide any subsequent analysis of their account. However, this did not preclude second round autobiographers from providing explanation for the contents of their bags and analysing their own practice. A total of 23 stories were collected and these are the ones analysed in this paper. There was a mix of males and females, ages ranged from early 20 s to 80 s and although the majority were British, there were German, Dutch and Canadian contributors. Most accounts were sent via email, but two people who did not use email were interviewed and the account written up by a reseacher. All authors were given pseudonyms.

\section{Mapping the writing onto Schön's stages of reflection}

These stages necessary for the bag writing task match well onto the stages of reflection on action in Schön's hierarchy of levels although not necessarily in this order:

1. Action. Looking into the bag(s).

2. Recording observations. Writing the bag day story. Listing what was in the bag or describing the objects or the bag itself.

3. Reflection-on-action (first reflection). Thinking about the bag contents and the reasons for taking these on the journey.

4. Second reflection. Interrogating self to understand and analyse the practice and produce new knowledge of the situation. This stage might signal that learning and a change in practice has occurred, or may occur.

However, the way these stories were written did not necessarily follow this model exactly. The order of these steps might depend on how the participant recorded observations and reflected whether starting from a descriptive list of objects or from an analytical position on why the objects were being transported. For those who were familiar with ICT, use the bag story might have been read and reread and reworked many times by the author before it was passed on by email. The process of reconfiguring text allows opportunities for reflection to occur whether conscious or unconscious. It seems probable that some of the reflection on reflection might have emerged from such a process of text re-construction.

The timescales could also differ; reflections on the bag stories could have been written down a split second after contents of bag were examined or several hours or days later when the piece of writing was being redrafted and finalised ready to send to the research group-one writer used the term 'with hindsight' so was clearly reappraising his own actions.

Nevertheless, everyone who completed a bag story will have gone through the first two stages, that is looking in the bag and listing or describing the bag and/or its contents as this was fundamental to the exercise. Many people in the study also provided an explanation for why they were behaving as they were which matches the third stage. These often prompted the beginnings of a second reflection on their behaviour through self-critique and it was here that emotional responses were evident.

The second reflection-on-action, the fourth and final stage, was not required of the second round of bag writers who were not asked to re-read their account and reflect upon it, although some did this 
prompted by an awareness of the audience who would be reading the account. One feature of writing autobiographically which seemed to encourage this second round of critical reflection was developing internal dialogue by drawing upon the perspective of others. I present some examples of how self-critique and internal dialogue emerged in these autobiographical writings next.

\section{Examples of learning through self-critique in autobiographical reflection}

It was possible to identify how self-critique can develop in autobiographical accounts: firstly, there was the start of a self-interrogation, secondly the beginnings of reflection on reflection through dialogue with the reader and thirdly an explicit second reflection through internal dialogue which prompted reappraisal of evidence and new action -in other words critical reflection on practice.

\section{Starting a dialogue with self which remains unresolved}

It was quite common for the bag authors to name the contents of their bags and provide the reader with their explanations for transporting these objects. A majority of writers also started to selfinterrogate to imply uncertainty about the efficacy of their own practice. For example, opening up a bag in this way and identifying the objects it contained prompted Lucy to ask herself thirteen questions including:

\section{Why 7 pens?}

Which of these items could I do without?

Why is the broken hair clip still in there l've taken it out a number of times?

I don't like my key ring, why don't I buy a new one?

She answered the questions about pens:

I'm so worried about not having a pen in case I need to remember something I pick them up where ever I go and keep putting them in.

She does not appear to have an answer for the other questions, at least not yet; she provides no rationale for carrying the items and her critique of self is implicit in her self-interrogation. Lucy clearly did the following:

1. Looked into her bag(s).

2. Recorded observations. Listing what was in the bag and describing the objects.

3. Reflection-on-action. She asked why the items were present with implied self criticism.

But, she did not reflect a second time on her initial reflection to answer the questions -apart from answering the pen question-and thus did not gain any new insight into her behaviour or propose new actions. The emotions of anxiety and frustration are clear from this account, as they were in many others, but here negative emotions remained unaddressed.

Ray carries a small bag as practical for him becuase he would be tempted to fill a large bag. $\mathrm{He}$ defends this practice against other men who taunt him for this feminine practice: 
I have been derided about the smallness of my bag ("like your handbag, Ray!") by men who speak in suggestive feminine tones. Why equate bag smallness with femininity?

Again he does not answer this question, but there is an implicit challenge to those who do equate small bags with femininity and who use gay stereotypes to mock his behaviour. There is the beginning of a dialogue here, perhaps with the reader, but it does not move beyond posing a question.

\section{Dialogue with the reader to achieve new insight into self}

Gay used this creative opportunity to write a poem which contained a list of items and some direct engagement with the reader. She is concerned about the quantity of medical things in her bag and she asks the reader: "have you fallen asleep yet?" She reflects that there are a lot of "in case" remedies:

How very sad (And true to age?) to have to almost fill a page with "in case" remedies:

Ibuprofen, Rizatriptan (migraine for relief of ),

Canestan ( for thrush), and (shhh)

Anti Diarrhoea capsules!

Plasters for an accident,

Zovirax for a cold sore.

Here she is regretful perhaps of the ailments which she perceives to be age related, and slightly embarrassed by the contents of her bag (indicated by the shhh and exclamation mark).

Her poem also contains a self dialogue in which she asks herself whether she is a hypochondriac then answers the question stating: "I AM a hypochondriac". She also describes her poem as "revealing" to the reader and that she is "obsessed" with herself and "slovenly". Again this is highly self critical, but she seems to be reinforcing an existing negative view of herself rather than gaining any new insight.

She ends with an imagined response from her reader (the researcher who requested the bag story from her), Pippa, and this helps her reflect again on what she has initially written:

OK! so let's take a look

At what l've written here, for Pippa.

"A Bag diary" was what she said

I'll bet she will be filled with dread when she sees this lot appear!

Oh dear..

Perhaps l'll go back and delete some ????

But does this imply that she might reconsider carrying so much in her bag and not just deleting items from her list? It is not possible to tell from the account alone. But, she is beginning a second reflection through imagining how the reader might react to her poem. Here she is reappraising evidence through Pippa's eyes a leading to suggested action of deleting some of the items from the poem (bag). 
Internal dialogue with imagined other(s): reappraisal of evidence and new actions

It is widely agreed that consultation with others is essential for critical reflection. The philosopher Sandra Harding (1991) has argued that viewing knowledge from multiple perspectives from others leads to greater objectivity and insight. She argues that better knowledge is obtained through not only consultation with others but also through viewing knowledge through the eyes of others. Thus, if the interpretations of others are not immediately accessible, then it might be possible for multiple perspectives to emerge from the self.

But, being self-critical in the above cases concentrated on identifying the inadequacies of self with little promise of improvement. Achieving a second reflection and thus a new perspective though dialogue between the author's account of experience and an imagined other's perspective can be powerful and in a few cases resulted in reappraisal of evidence and development of new practice. In Evadne's story, the bag writes the narrative and thus the author is continually re-interpreting her experience from another's perspective. The bag as the narrator is highly critical of its owner:

There are unspeakable things in my corners. Old crumbs of chocolate. Odds and ends of Kleenex. It doesn't occur to her to turn me inside out now and then and give me a brush.

This an oblique method of self-reflection in which the author is critiquing her own behaviour and considering an action she could take: clearing out the bag and brushing it down. Here is evidence that a dialogue moves the writer on from the self-denigrating confessions of undesirable practice that were prevalent in many of the stories to an understanding of how changes might be made.

In another example, the critical voice of the bag suggests an improvement in organisational practice by keeping keys in a separate compartment:

She THINKS she puts them (her keys) in my small front pocket which would be good if she did. But she drops them into me all anyhow and then it's scrabble, scrabble, scrabble, and, "Where are my house keys"?

Later, Evadne demonstrates how the bag voice enables internal dialogue to take place. She describes a visit to her partner is in hospital through the narrative of the bag:

When we go shopping, she's always taking one (a notebook) out so she can write something .... She's a great one for having 'ideas'. Can you imagine! There is her co-creature (husband) lying in agony on a stretcher and she has an idea! To be fair, he wasn't in agony, he was slightly drugged and happily reading a paperback book.

There have clearly been several reflective stages in this writing which can be matched with Schön's stages although not necessarily in this order:

1. Action. Looking into the bag.

2. Recording observations, in this case to identify pieces of paper in the bag

3. Reflection-in-action to explain her behaviour and critique herself for having 'ideas' while her partner is ill using the 'bag' voice. 
4. Second reflection made by Evadne reconsidering the evidence and tempering the negatively critical 'bag' voice to conclude that jotting down her thoughts is not a practice to feel guilty about because her husband is quite content.

A reappraisal of the situation from two perspectives is possible here because of the narrative device which enables a dialogue between bag owner and bag. This is of course really an imaginary internal dialogue with a different self represented by the persona of the bag, but nevertheless it successfully mimics the process of reflecting and learning through dialogue with another person and prompts both suggestions for new practice, such as putting the keys in the front pocket, and prevents the writer from being excessively self-demeaning.

We do not know from this account whether or not the writer's intentions to change practice were fulfilled. However, in one of the stories there were clear references to change in practice as a direct result of re-reflection during the writing process. Samuel describes a range of bags he used for the 'bag' day including paper bags and plastic carrier bags as well as a work-bag. His account contains a light-hearted confession about hiding pastry bags from his female partner so that she will not know that he is flouting a healthy eating plan. But, perhaps to inject more humour into his account, he also describes how the reflective process of writing prompted him to reconsider the thoroughness of his practice of hiding evidence of unhealthy eating and consequently take new action:

Looking around on the floor right now I see that in helping Project PATT I've unwittingly dropped some tell tale pastry on the floor - I am now so worried that 'the boss' might see this so am going to take a break and hoover it up and dispose of the paper bags .... That's better.

His apparent reflection-in -action while taking part in the bag writing project, done for the purposes of the PATT team, produces a new action to hide the more subtle evidence of his forbidden sugar consumption-the crumbs- which he otherwise might have omitted to do. His awareness of the consequences of his actions on others seems heightened by writing the account and the emotional aspects are clear in this account to -the anxiety and then the relief that the evidence has gone.

Thus, here there is clear evidence here of a second reflection occurring through telling the reader about the process of writing which results in taking new action. But, there is also the possibility of reflection leading to taking action at a later time. Several of the researchers reported that they had made changes to their practice at a later stage as a direct result of taking part in the autobiographical writing project, including myself.

\section{Learning from the bag stories? Using internal dialogue to improve critical reflection in professional development}

These examples build on Schön's work on the importance of dialogue in reflective learning to suggest that autobiographical writing about everyday life can be very productive. Using an autobiographical approach to writing meant it was intuitive for many authors to begin an internal dialogue while writing the story and ask themselves questions, and although these were not always explicitly answered, questioning triggered some new self-understanding. Awareness of the reader 
also encouraged a deeper self-critique in the beginnings of a second reflection. But, it was writing from another's perspective which led to new interpretations of practice and actions. Evadne's narrative by the bag gave her a good opportunity to have a conversation with herself and avoid becoming stuck in negative self-criticism and guilt. Other literary devices such as use of humour in Samuel's imagined conversation about the writing process with the research project team could also prompt new action to be taken.

Reflection through autobiographical writing could usefully be applied to professional practice. Reflective practice does not come easily to everyone and some people might be resistant to emotional challenges as I mentioned earlier. Based on this project, I have explored ways of helping teaching staff with reflective writing and found that both using everyday practice as a trigger and using internal dialogue are useful tools of facilitators working with groups of practitioners.

Firstly, I gave new professional teachers on a training course a shortened version of the 'what's in your bag' exercise to initiate a discussion about critical reflection. I suggested that they might use the perspective of the bag to gain some deeper insight. Using an everyday example with the potential for humour that we saw above, diffused some of the anxiety around writing a reflective statement for assessment of teaching practice. The trainees found it relatively easy, and even entertaining, to be self-critical in talking about everyday practice and considering change. It not only provide insight into reappraisal of evidence through the physical process of taking out items from the bag and sharing the contents with others, but also helped with understanding of the process of reflecting on professional practice and appreciate that this is an emotionally charged process. Several of them went on to use the technique with their own students and the 'what's in your bag' activity has gained interest from educational developers in the UK (Hughes, 2006).

Secondly, inspired by the creativity of the 'bag as author' stories, I encouraged trainee teachers to write stories from different perspectives. For reflections on teaching experience, I suggest that teachers write accounts of their lessons from a student perspective using both literature on how people learn and observations of how the students were responding for ideas. With help from peers, they then wrote a fictitious dialogue with the students about the event about how to make changes. Seeing an event from a student perspective is a very powerful way of encouraging a more critical reflection of self and is potentially much more challenging than writing a single perspective descriptive account of the event. This is clearly a more serious activity than the 'bag' story writing, but introducing professional learners to ways in which they can set up an internal dialogue is particularly useful for those who are new to reflective practice as these people were. The emotional and professional stakes may be high here, and not all trainees will take the risk of putting a candid account of problems they have experienced in the classroom on paper for assessment, and so the role of peers or mentors in facilitating reflection cannot be underestimated. Nevertheless, using internal dialogue in autobiographical accounts is a technique which can be very helpful as a starting point. As well as teaching, I would also suggest that deliberately writing from another's perspective could be a valuable tool for other professions such as in medical professions and social work.

Finally, new technologies might offer enhanced possibilities for self-dialogue to promote critical reflection. Blogs have potential for keeping records of self-expression over time with feedback from others (Mason \& Rennie, 2008 ). But, a contributor to a blog could be another self. For example, to help make a decision on whether or not to apply for a new job, I set up a blog with two contributors 
with different names and 'voices' one was me and the other my 'boss'. The fictitious dialogue on the blog over a week or so helped me explore why I wished to apply for the post and whether there was a chance of my succeeding. It also helped me deal with my emotional response of guilt in 'letting' down the people with whom I was working-including my 'boss'. Of course this was not the only way I made the decision, there were many other conversations on the way, but using a blog was a different approach to being self-critical that added a new dimension.

\section{Conclusion}

We are all so caught up in our 'lived' experience that it is never easy to stand back and get a rounded and informed picture of self. Autobiographical writing for public consumption provides opportunity for learning through reflection. Our 'bag day' autobiographers have shown that Schön's concept of professional reflective practitioner can apply to everyday practice and that the creative writing process may produce critical thinking about practice through using internal dialogues.

The aim of this project was not to promote self-reflection and thus there was no encouragement of dialogue with peers or requirement for deeper interpretation of one's own practice. Learning through written reflection on everyday practice might not suit everyone, and it would be useful to compare autobiographical writing with other methods. More exploration of other ways of using internal dialogue to help gain insight into the perspectives of others could also be fruitful.

The 'bag day' stories illustrate the creativity and imagination that can materialise from everyday autobiographical writing can help authors in becoming more critically reflective of practice. These rich examples have given us a glimpse of the potential for internal dialogue in autobiographical writing to obtain a balanced self-critique through reappraisal of evidence and the possibility of challenging both everyday and professional practice.

Acknowledgments: PATT (People and Their Things) was an interdisciplinary international research project and I wish to thank the members of the team who read drafts of this article and provided encouraging feedback. My appreciation also goes to the reviewers for their constructive comments.

\section{Bibliography}

Beard, C., Clegg, S. \& Smith, K. (2007). Acknowledging the affective in higher education. British Educational Research Journal, 33(2), 235-252.

Brockbank, A. \& McGill, I. (1998). Facilitating Reflective Learning in Higher Education. SRHE and OUP: Buckingham.

Clegg, S., Tan, J. \& Saeidi, S. (2002). Reflecting or Acting? Reflective Practice and Continuing Professional Development in Higher Education. Reflective Practice 3(1):131-146.

Dunning, D. (2004). Flawed Self-Assessment: implications for Health, Education and the Workplace. Psychological Science in the Public Interest, 5(3), 69-99.

Franklin, B (1750) quoted in Keith M. (1994) (Ed.). Webster's Electronic Quotebase. 
Harding, S. (1991). Whose Science? Whose knowledge? Thinking from Women's Lives. Milton Keynes: Open University Press.

Henwood, F., Hughes, G., Kennedy, H. Miller, N. \& Wyatt, S. (2001) Cyborg lives in context: writing women's technobiographies. In Henwood, F., Kennedy, H. and Miller, N (Eds.), Cyborg Lives? Women's Technobiographies (pp.11-34). York: Raw Nerve Books pp.11-34.

Hughes, G. (2006). What's in your bag? How reflection on everyday practice can help us become more self-critical Educational Developments Issue 7(4),7-9.

Hobbs, V. (2007). Doing it or faking it? Can reflective practice be forced?, Reflective Practice, 8(3), 405-417.

Husu, J., Toom, A. and Patrikainen, S. (2008). Reflective Practice, 9(1), 3 7-51.

Jarvis, P. (1995). Adult and continuing education: theory and practice. London: Routledge.

Mason, R. \& Rennie, F. (2008). E-Learning and Social Networking Handbook Resources for Higher Education. London: Routledge.

Millett, K (1974). Flying. New York: Ballantine Books.

Moon, J. (2000). Reflection in Learning and Professional Development: Theory and Practice. London: Routledge Falmer.

Moon, J. (2007). Critical Thinking: An exploration of theory and practice. London: Routledge.

Mortiboys, A. (2005). Teaching with Emotional Intelligence. London: Routledge.

Pennebaker, J. W. and Graybeal, A. (2001) Patterns of Natural Language Use: Disclosure, Personality, and Social Integration. Current Directions in Psychological Science, 10(3), 90-93

Schön, D. (1991). The Reflective Practitioner: How Professionals Think in Action. $\left(2^{\text {nd }}\right.$ ed.) Aldershot: Arena (Ashgate).

Schön, D. (1984). Educating the Reflective Practitioner. Jossey-Bass Publishers: San Francisco.

Stanely, L. (1992). The Auto/Biographical I: The Theory and Practice of Feminist Auto/Biography. Manchester: Manchester University Press.

Steedman, C. (1987). Landscape for a Good Woman: A story of Two Lives. London: Virago.

Usher, R. \& Edwards, R. (2000). Globalisation and Pedagogy: space, place and identity. London: Routledge. 
Wenger, E. (1998). Communities of Practice: Learning, Meaning and Identity. New York: Cambridge University Press. 